\title{
Analisis Cluster Ensemble dalam Pengelompokan Kabupaten/Kota di Provinsi Sulawesi Selatan Berdasarkan Indikator Kinerja Pembangunan Ekonomi Daerah
}

\author{
Adrian Aqil Yusfar*, Muhammad Arif Tiro, \& Sudarmin \\ Program Studi Statistika, Fakultas Matematika dan Ilmu Pengetahuan Alam, Universitas Negeri Makassar, Indonesia
}

Keywords: Cluster, Cluster Ensemble, Group Performance Evaluation, Performance, Regional Economic

\begin{abstract}
:
Cluster analysis or group analysis is an analysis method to classify objects of observation into several groups based on their characteristics. Conventional methods namely Hierarchy and Non-Hierarchy are used in the formation of the initial group. However, the results of the grouping formed had mixed results so that the Cluster Ensemble analysis was then used to obtain a good final grouping. The Cluster Ensemble with the Link-Based Cluster Ensemble approach with the Connected Triple Based Similarity (CTS) method resulted in three final group divisions. The evaluation of the grouping performance used, namely Compactness and Davies-Bouldin, stated that the Cluster Ensemble was better than the hierarchical and nonhierarchical methods. The final group that has been formed is described using the average value for each variable in the district / city in South Sulawesi Province. The first group has the characteristics of regional economic development performance that is better than the second and third groups, but for the third group has the lowest characteristics of regional economic development performance from the first and second groups.
\end{abstract}

\section{Pendahuluan}

Indonesia sebagai negara dengan keragaman yang tinggi memiliki potensi dari setiap wilayah yang beraneka ragam dan berbeda beda. Dari keragaman tersebut menyebabkan tidak meratanya pembangunan antar daerah. Pembangunan adalah suatu proses multidimensional yang melibatkan berbagai perubahan mendasar dalam struktur sosial, tingkah laku sosial dan institusi sosial, di samping akselerasi pertumbuhan ekonomi, pemerataan ketimpangan pendapatan, serta pemberantasan kemiskinan (Todaro, 2003). Tercapainya pembangunan sebuah wilayah tersebut salah satu yang harus dilaksanakan ialah pembangunan ekonomi. Tujuannya ialah demi meningkatkan taraf hidup dan kesejahteraan rakyatnya.

Pertumbuhan ekonomi akan tercapai dengan baik apabila pemerataan antar wilayah tidak saling tumpah tindih. Dari unit terkecil hingga unit terbesar wilayah yakni sebuah daerah hendaknya lebih dipantau dengan seksama oleh pemerintah agar pertumbuhan ekonomi dan pendapatan daerah tersebar merata kepada seluruh masyarakat. Pembangunan ekonomi daerah merupakan salah satu rangkaian upaya dimana pemerintah daerah dan masyarakatnya mengelola sumber daya-sumber daya yang ada dan membentuk suatu pola kemitraan antara pemerintah daerah dengan sektor swasta untuk menciptakan suatu lapangan kerja baru dan merangsang perkembangan kegiatan ekonomi dalam wilayah tersebut (Arsyad, 2010).

\footnotetext{
* Corresponding author.

E-mail address: ianyusfary@gmail.com
} 
Provinsi Sulawesi Selatan sebagai provinsi dengan pertumbuhan ekonomi tertinggi dan menjadi provinsi dengan kontribusi paling besar dalam perekonomian wilayah diluar pulau jawa. Menurut (BPS, 2019) pertumbuhan ekonomi Sulawesi Selatan tahun 2018 sebesar 7,04\% yakni mengalami pertumbuhan ekonomi terendah dalam 3 tahun terakhir apabila dihitung pada tahun 2016 sebesar 7,42\% dan pada tahun 2017 sebesar 7,23\% dengan ini mengindikasikan bahwa pertumbuhan ekonomi Provinsi Sulawesi Selatan dari tahun ketahun mengalami penurunan dibandingkan dengan pertumbuhan ekonomi tertinggi yang berada di pulau jawa yakni DKI Jakarta sebesar 6,13\%, Jawa Barat $5,71 \%$, dan Jawa Timur 5,51\% pada tahun 2018. Sedangkan partisipasi ekonomi tertinggi yakni yang ada di pulau jawa yaitu DKI Jakarta sebesar 17,35\%, Jawa Barat 13,09\%, dan Jawa Timur 14,61\% dibandingkan dengan Provinsi Sulawesi Selatan sebesar 3,61\% yang merupakan salah satu provinsi diluar pulau jawa yang tertinggi. Produk Domestik Regional Bruto (PDRB) menjadi sektor perekonomian dalam penentuan kebijakan daerah di kabupaten/kota di Provinsi Sulawesi Selatan. Jika dilihat dari rerata PDRB akan berbeda atau tidak merata disetiap daerah sehingga ini menjadi salah satu ketimpangan ekonomi antar kabupaten/kota yang diakibatkan perbedaan pusat pertumbuhan wilayah tersebut. Dari ketimpangan yang terjadi salah satu solusi yang dapat dilakukan ialah mengelompokkan kabupaten/kota di Provinsi Sulawesi Selatan berdasarkan indikator kinerja pembangunan ekonomi daerah sebagai informasi dan evaluasi bagi pemerintah dalam menentukan kebijakan.

Dalam teknik analisis statistik, metode pengelompokan yang dapat digunakan ialah analisis Cluster. Analisis pengelompokan (Cluster) merupakan teknik primitif, yakni tidak membuat asumsi tentang banyak atau struktur kelompok (Tiro, dkk. 2010). Pengelompokan tersebut dilakukan berdasarkan kemiripan atau jarak. Pada Analisis Cluster terdapat banyak metode yang dapat diterapkan yakni metode konvensional berupa Analisis Cluster berhierarki dan non berhierarki, namun metode yang beragam tersebut menghasilkan solusi kelompok yang beragam pula sehingga dalam kondisi ini solusi pengelompokan akan sulit ditentukan. Solusinya ialah membandingkan hasil kelompok tersebut dari hasil yang telah didapatkan. Sekumpulan solusi kelompok yang diperoleh dari metode yang beragam bersifat saling melengkapi sehingga cara efektif untuk memperoleh hasil kelompok yang baik adalah mengkombinasikan solusi tersebut (Hu \& Yoo, 2004). Cluster Ensemble adalah sebuah metode yang digunakan untuk mengombinasikan sekumpulan solusi kelompok (Strehl \& Ghosh, 2002). Penelitian yang dilakukan oleh (Strehl \& Ghosh, 2002) menunjukkan bahwa metode Cluster Ensemble mampu meningkatkan kualitas dan ketahanan solusi kelompok. Berdasarkan kelebihan tersebut peneliti menerapkan Analisis Cluster Ensemble untuk mengelompokkan kabupaten/kota di Provinsi Sulawesi Selatan berdasarkan indikator kinerja pembangunan ekonomi daerah.

\section{Tinjauan Pustaka}

\subsection{Analisis Cluster}

Analisis kelompok merupakan teknik peubah ganda yang mempunyai tujuan utama untuk mengelompokkan objekobjek berdasarkan kemiripan karakteristik yang dimilikinya. Karakteristik objek-objek dalam suatu kelompok memiliki tingkat kemiripan yang tinggi, sedangkan karakteristik antar objek pada suatu kelompok dengan kelompok lain memiliki tingkat kemiripan yang rendah. Dengan kata lain, keragaman dalam suatu kelompok minimum sedangkan antar keragaman antar kelompok maksimum (Mattjik \& Sumertajaya, 2011). Sedangkan menurut (Babin \& Anderson, 2014) Analisis Cluster adalah sekompok Teknik multivariat yang tujuan utamanya adalah untuk mengelompokkan objek berdasarkan pada karakteristik yang mereka miliki. Analisis Cluster atau analisis kelompok merupakan sebuah metode analisis untuk mengelompokkan objek-objek pengamatan menjadi beberapa kelompok berdasarkan karakteristik-karakteristik yang dimiliki (Putri, 2017). Struktur data untuk analisis cluster dengan $n$ pengamatan dan $m$ variabel ditunjukkan sebagai berikut.

Tabel 1 Struktur data analisis cluster

\begin{tabular}{cccccc}
\hline Pengamatan ke- & $X_{1}$ & $X_{2}$ & $X_{3}$ & $\cdots$ & $X_{m}$ \\
\hline 1 & $X_{11}$ & $X_{21}$ & $X_{31}$ & $\cdots$ & $X_{m 1}$ \\
2 & $X_{12}$ & $X_{22}$ & $X_{32}$ & $\cdots$ & $X_{m 2}$ \\
3 & $X_{13}$ & $X_{23}$ & $X_{33}$ & $\cdots$ & $X_{m 3}$ \\
$\vdots$ & $\vdots$ & $\vdots$ & $\vdots$ & $\ddots$ & $\vdots$ \\
$n$ & $X_{1 n}$ & $X_{2 n}$ & $X_{3 n}$ & $\cdots$ & $X_{m n}$ \\
\hline
\end{tabular}


Pendekatan yang paling biasa dilakukan dalam mengukur kemiripan dinyatakan dalam jarak (distance) antara pasangan objek (Supranto, 2004). Dari variabel yang memiliki sifat yang dekat dengan variabel lain dinyatakan dengan fungsi jarak. Jarak yang paling umum digunakan adalah jarak Euclidean. Perhitungannya sebagai berikut (Johnson \& Winchern, 2007):

$$
d\left(x_{i}, x_{j}\right)=\sqrt{\sum_{k=1}^{p}\left(x_{i k}-x_{j k}\right)^{2}}
$$

Keterangan:

$i=1,2, \ldots, \mathrm{n}$ dan $j=1,2, \ldots, \mathrm{n}$ dengan $i \neq j$

$d\left(x_{i}, x_{j}\right)=$ jarak antara dua objek $i$ dan $j$

$x_{i k}=$ nilai objek $i$ pada variabel $k$

$x_{j k}=$ nilai objek $j$ pada variabel $k$

Metode ini memiliki beberapa keuntungan, antara lain jarak dari 2 objek apa saja tidak dipengaruhi oleh penambahan dari objek baru untuk di analisis, yang mungkin merupakan pencilan. Namun demikian, jarak bisa menjadi sangat besar, disebabkan hanya karena perbedaan skala. Hasil dari jarak Euclidean atau kuadrat Euclidean (dihitung dari dimensi ganda) bisa sangat berbeda, dan konsekuensinya, hasil dari analisis cluster mungkin menjadi berbeda.

Metode pengelompokan terbagi menjadi dua jenis (Johnson \& Winchern, 2007), yakni metode berhierarki dan non hierarki:

\section{Metode berhierarki}

Metode ini digunakan untuk mengelompokkan pengamatan secara terstuktur berdasarkan kemiripan sifatnya dan kelompok yang diinginkan belum diketahui banyaknya. Ada dua cara untuk mendapatkan kelompok dengan metode pengelompokan hierarki yaitu dengan cara penggabungan (aglomerative) dan pemisahan kelompok (devisive) (Mattjik \& Sumertajaya, 2011). Cara penggabungan, pada awal pengelompokan setiap objek pengamatan berasal dari kelompok berbeda, kemudian objek yang saling berdekatan dikelompokkan sehingga objek tersebut berada pada kelompok yang sama. Begitupun sebaliknya dengan cara pemisahan.

\section{a Keterhubungan Tunggal (Single Linkage/Nearest Neighbor)}

Metode Single Linkage atau disebut juga dengan motode pautan tunggal, jarak antara dua Cluster (kelompok) dapat ditentukan dari dua objek berpasangan yang memiliki kesamaan atau memiliki jarak terdekat (nearest neighbor) dalam Cluster yang berbeda. Untuk menghitung jarak Cluster dengan Cluster-Cluster yang lain dapat dirumuskan dengan:

Keterangan:

$$
d_{(u v) w}=\min \left(d_{u w}, d_{u w}\right)
$$

$d_{(u v) w}=$ jarak antara kelompok $(u v)$ dan kelompok $w$

$d_{u v}, d_{u w}=$ jarak tetangga terdekat kelompok $u$ dan $w$, dan kelompok $v$ dan $w$

b Keterhubungan menyeluruh (Complete Linkage/Furthest Neighbor)

Jarak antar Cluster pada metode Complete Linkage atau disebut juga metode pautan lengkap, ditentukan dari jarak terjauh antara dua objek pada Cluster yang berbeda (furthest neighbor). Metode ini dapat digunakan dengan baik untuk kasus dimana obyek-obyek yang ada berasal dari kelompok yang benar-benar berbeda. Dapat dirumuskan dengan:

$$
d_{(u v) w}=\max \left(d_{u w}, d_{u w}\right)
$$

c Pautan Centroid, jarak antara dua kelompok diukur sebagai jarak Euclidian antara kedua rataan (centroid) kelompok.

$$
\begin{gathered}
d_{(u v) w}=\frac{n_{u}}{n_{u}+n_{v}} d_{u w}+\frac{n_{v}}{n_{v}+n_{v w}} d_{v w}+ \\
-\frac{n_{u} n_{v}}{\left(n_{u}+n_{v}\right)^{2}} d_{u v}
\end{gathered}
$$


d Keterhubungan Rataan (Average Linkage)

Jarak antar Cluster pada metode Average Linkage atau disebut juga metode pautan rataan, ditentukan dari ratarata jarak seluruh objek suatu Cluster terhadap seluruh objek pada Cluster lainnya. Pada berbagai keadaan, metode ini dianggap lebih stabil dibandingkan dengan kedua metode di atas dapat dirumuskan dengan:

$$
d_{(u v) w}=\operatorname{average}\left(d_{u w}, d_{u w}\right)
$$

e Ward Jarak antar kelompok dievaluasi dengan meminimumkan peningkatan jumlah kuadrat galat pada setiap tahap pengelompokan.

$$
\begin{aligned}
d_{(u v) w}= & \frac{n_{u}+n_{w}}{n_{w}+n_{(u, v)}} d_{u w}+\frac{n_{v}+n_{w}}{n_{v}+n_{(u, v)}} d_{v w}+ \\
& -\frac{n_{w}}{n_{w}+n_{(u, v)}} d_{u v}
\end{aligned}
$$

Keterangan: $n_{u}, n_{v}, n_{w}=$ jumlah kelompok ke- $u$, ke- $v$, dan ke- $w$

Secara umum, algoritma untuk metode pengelompokan hierarki adalah:

1. Tentukan matriks jarak antar data atau kelompok

2. Gabungkan dua data atau kelompok terdekat ke dalam kelompok yang baru

3. Tentukan kembali matrik jarak tersebut. Lakukan langkah 2 dan 3 sampai semua data masuk dalam satu kelompok

Hasil pengelompokan tersebut dapat digambarkan dengan dendrogram atau vicicle plot yakni representasi matematis yang memuat gambar dari prosedur pengelompokan yang telah terbentuk (Everitt, dkk. 2011). Jumlah kelompok yang terbentuk ditentukan dari dendrogram yang terjadi dan tergantung subjektivitas peneliti. Dalam pembentukan cluster setiap objek hanya boleh masuk kedalam satu cluster saja sehingga tidak terjadi tumpeng tindih atau overlapping (Susanto, 2009).

2. Metode non berhierarki

Metode berkelompok non berhierarki digunakan bila banyaknya kelompok yang akan dibentuk telah ditentukan. Salah satu metode dalam metode pengelompokan non berhierarki yaitu metode k-means. Pengelompokan non hierarki lebih cepat daripada metode hierarki dan lebih menguntungkan jika jumlah objek/kasus atau observasi besar sekali (sampel besar). Penggunaan $k$-means untuk menjelaskan algoritma dalam penentuan suatu objek ke dalam kelompok tertentu berdasarkan rataan terdekat. Dalam bentuk yang paling sederhana, proses ini terdiri dari tiga tahap (Johnson \& Winchern, 2007):

1. Bagi objek-objek tersebut ke dalam $k$ kelompok awal.

2. Masukkan tiap objek ke suatu kelompok berdasarkan rataan terdekat. Penentuan jarak menggunakan Euclidean. Hitung kembali rataan untuk kelompok yang mendapat objek dan yang kehilangan objek.

3. Ulangi langkah 2 sampai tidak ada lagi pemindahan objek antar kelompok. Dalam membagi objek ke dalam $k$ kelompok permulaan (pada langkah 1), sebelumnya dapat ditentukan rataan untuk $k$ inisial, baru kemudian dilanjutkan dengan langkah berikutnya.

Penentuan terakhir suatu objek ke suatu kelompok tertentu tidak tergantung dari $k$ inisial yang pertama kali ditentukan.

\subsection{Cluster Ensemble}

Strehl dan Gosh (2002) memperkenalkan sebuah metode yang digunakan untuk mengombinasikan sekumpulan solusi kelompok yang disebut Cluster Ensemble. Penelitian yang dilakukan oleh Strehl dan Gosh (2002) menunjukkan bahwa metode Cluster Ensemble mampu meningkatkan kualitas dan ketahanan solusi kelompok. Cluster Ensemble merupakan metode pengelompokan data dengan menggabungkan hasil pengelompokan dari beberapa metode berbeda sehingga diperoleh solusi gabungan sebagai solusi akhir (Nuraidah, 2014). Pembentukan sebuah hasil yang memiliki kualitas yang baik dari adanya keragaman solusi sebuah kelompok yang dihasilkan terhadap berbagai metode sehingga Cluster Ensemble digunakan. 
Pembentukan kelompok Cluster Ensemble dilakukan dengan mengkombinasikan berbagai solusi dari berbagai metode pengelompokan hingga diperoleh satu pengelompokan akhir yang lebih baik. Pengelompokan objek dengan metode Cluster Ensemble dilakukan dalam dua tahap (Iam-on dan Garret, 2010), yaitu:

1. Membentuk anggota ensemble yang anggotanya adalah solusi dari berbagai metode pengelompokan yang berbeda.

2. Mengombinasikan seluruh anggota ensemble untuk memperoleh satu solusi akhir yang dinamakan fungsi Consensus.

Dalam Cluster Ensemble dikenal sebuah fungsi yang dinamakan fungsi consensus. Ide pembentukan consensus untuk menggabungkan perspektif data yang ada menjadi partisi yang stabil. Fungsi consensus terbagi menjadi dua tahapan (Bejar, 2020):

a Hasil masing masing metode cluster individual digabungkan secara partisi $P=\left\{\pi^{1}, \pi^{2}, \ldots, \pi^{n}\right\}$.

b Partisi yang ada digabungkan untuk menghasilkan partisi akhir dengan $P^{1}=\left\{c_{1}^{1}, c_{2}^{1}, \ldots, c_{k_{1}}^{1}\right\} \cdots P^{n}=$ $\left\{c_{1}^{n}, c_{2}^{n}, \ldots, c_{k_{n}}^{n}\right\}$

Fungsi Consensus memiliki beragam algoritma, salah satunya algoritma pairwaise similarity. Ide dasar dari algoritma ini adalah menggunakan hubungan kesamaan berpasangan antara semua titik data. Untuk suatu data $X=$ $\left\{x_{1}, x_{2}, \ldots, x_{n}\right\}$, akan dibangun Cluster Ensemble $\pi=\left\{\pi_{1}, \pi_{2}, \ldots \pi_{M}\right\}$ dengan melakukan pengelompokan dasar $M$ ke data $X$. Lalu, matriks kesamaan berukuran $N \times N$ dibangun untuk setiap anggota Ensemble. Input dalam setiap matriks ini merupakan hubungan antara dua titik data. Lebih tepatnya, kesamaan antara dua titik data $x_{i}, x_{j} \in X$ dari pengelompokan ke-m (Ristiyanti, 2017). Matriks kesamaan ini dibangun menggunakan algoritma Link-Based Cluster Ensemble.

Berikut algoritma dan ilustrasi perhitungan Link-Based Cluster Ensemble dimulai dari transformasi anggota ensemble menjadi Binary Association Matrix (BM) hingga pembentukan matriks CTS dan matriks jarak akhir.

1. Membangun anggota ensemble dengan membentuk pelabelan ulang. Ilustrasi yang digunakan memuat 5 sampel dengan 2 metode pengelompokan $(\pi)$.

2. Pelabelan ulang yang terbentuk ditransformasi menjadi Binary Association Matrix (BM) dengan matriks berukuran $N \times P$. N sebagai baris jumlah pengamatan dan $P$ sebagai kolom label. Selanjutnya mengisi kolom dengan satu apabila bersesuaian dengan label dan yang tidak bersesuaian diisi dengan angka nol.

3. Membentuk matriks pembobot dengan langkah sebagai berikut:

a Membentuk matriks $(w)$ dengan persamaan

$$
w_{i j}=\frac{\left|X_{C_{i}} \cap X_{C_{j}}\right|}{\left|X_{C_{i}} \cup X_{C_{j}}\right|}
$$

Keterangan: $X_{C_{i}}=$ unsur objek ke- $i$ pada matriks BM

b Membentuk matriks WCT (Weight Connected Triple) dengan persamaan

Keterangan:

$$
W C T_{i j}=\sum_{k=1}^{q} \min \left(w_{i k}, w_{j k}\right)
$$

$q=$ jumlah label.

$$
\operatorname{Sim}^{W C T}(\mathrm{i}, \mathrm{j})=\frac{W C T_{i j}}{W C T_{\max }}
$$

$W C T_{\max }=$ adalah nilai tertinggi yang berada pada matriks WCT.

c Membuat matriks kesamaan

Keterangan:

$$
S_{m}\left(x_{i}, x_{j}\right)=\left\{\begin{array}{cl}
1 & \text { Jika } C\left(\mathrm{x}_{\mathrm{i}}\right)=\mathrm{C}\left(\mathrm{x}_{\mathrm{j}}\right) \\
\operatorname{Sim}^{W C T}\left(C\left(x_{i}\right), C\left(x_{j}\right)\right) \times \mathrm{DC} & \text { lainnya }
\end{array}\right.
$$

$S_{m}\left(x_{i}, x_{j}\right)=$ nilai kesamaan antara objek ke- $i$ dengan objek ke- $j$ pada algoritma metode pengelompokan ke- $m$.

$\operatorname{Sim}^{W C T}\left(\mathrm{C}\left(x_{i}\right), \mathrm{C}\left(x_{j}\right)\right)=$ nilai kesamaan antara label objek ke- $i$ dengan label objek ke- $j$.

$D C=$ tingkat kepercayaan menerima dua objek non-identik sebagai dua objek yang serupa, $D C \in(0,1]$.

Berdasarkan rangkaian persamaan tersebut matriks kesamaan dapat diperoleh dengan cara:

$$
\operatorname{CTS}\left(x_{i}, x_{j}\right)=\frac{1}{M} \sum_{m=1}^{M} S_{m}\left(x_{i}, x_{j}\right)
$$


Keterangan: $M=$ jumlah kelompok yang terbentuk pada metode pengelompokan ke- $m$.

d Mentransformasi matriks kesamaan menjadi matriks jarak

$$
d_{i j}=1-\operatorname{CTS}\left(x_{i}, x_{j}\right)
$$

\subsection{Evaluasi Kualitas Kelompok}

Setelah hasil kelompok diperoleh, untuk melihat kualitas struktur data dari kelompok yang terbentuk dapat dinilai menggunakan berbagai jenis ukuran validitas (Iam-on dan Garret 2010). Terdapat dua kategori evaluasi yang akan digunakan yaitu:

\section{Compactness $(\mathrm{CP})$}

Kategori evaluasi CP mengukur jarak rata-rata antara setiap pasangan titik data yang termasuk dalam kelompok yang sama.

Keterangan:

$$
C P\left(\pi^{*}\right)=\frac{1}{N} \sum_{k=1}^{K} n_{k}\left(\frac{\sum_{x_{i}, x_{j} \in C_{k}} d\left(x_{i}, x_{j}\right)}{n_{k}\left(n_{k}-1\right) / 2}\right)
$$

$k=$ jumlah kelompok yang terbentuk dalam pengelompokan akhir.

$n_{k}=$ jumlah data yang termasuk ke dalam kelompok ke- $k$.

$d\left(x_{i}, x_{j}\right)=$ adalah jarak antara objek ke- $i$ dan objek ke- $j$. $\mathrm{N}$ adalah jumlah seluruh objek.

Jika nilai dari indeks CP menghasilkan nilai yang rendah berarti struktur dari kelompok yang terbentuk bagus (Iam-on dan Garret 2010).

2. Davies-Bouldin (DB)

Indeks DB mengukur rata-rata kesamaan antara masing-masing kelompok yang paling mirip (Iam-on dan Garret 2010). $R_{i j}$ dirumuskan sebagai berikut:

$$
R_{i j}=\frac{s_{i}+s_{j}}{d_{i j}}
$$

Dengan $d_{i j}=d\left(v_{i}, v_{j}\right)$

$$
s_{i}=\frac{1}{\left|C_{i}\right|} \sum_{\forall x \in C_{i}} d\left(x, v_{i}\right)
$$

Sehingga dapat diperoleh indeks DB yaitu:

$$
D B\left(\pi^{*}\right)=\frac{1}{k} \sum_{i=1}^{k} R_{i}
$$

Dengan $R_{i}=\max _{j=1 \ldots k, i \neq j} R_{i j}$

Jika nilai dari indeks DB menghasilkan nilai yang rendah hal tersebut menunjukkan bahwa struktur dari kelompok yang terbentuk baik dibandingkan dengan partisi data sebelumnya (Iam-on dan Garret 2010).

\subsection{Pembangunan Ekonomi Daerah}

Pembangunan nasional sebuah negara diatur dalam Undang Undang Nomor 25 Tahun 2004 tentang sistem perencanaan pembangunan nasional. Pembangunan adalah suatu proses multidimensional yang melibatkan berbagai perubahan mendasar dalam struktur sosial, tingkah laku sosial dan institusi sosial, di samping akselerasi pertumbuhan ekonomi, pemerataan ketimpangan pendapatan, serta pemberantasan kemiskinan (Todaro, 2003). Tercapainya pembangunan sebuah wilayah tersebut salah satu yang harus dilaksanakan ialah pembangunan ekonomi. Pembangunan ekonomi didefinisikan sebagai suatu proses yang menyebabkan kenaikan pendapatan rill per kapita penduduk suatu negara dalam jangka Panjang yang disertai oleh perbaikan system kelembagaan (Arsyad, 2010).

Pertumbuhan ekonomi adalah proses perubahan kondisi perekonomian suatu negara secara berkesinambungan menuju keadaan yang lebih baik selama periode tertentu. Pertumbuhan ekonomi dapat diartikan juga sebagai proses kenaikan kapasitas produksi suatu perekonomian yang diwujudkan dalam bentuk kenaikan pendapatan nasional. Adanya pertumbuhan ekonomi merupakan indikasi keberhasilan pembangunan ekonomi. Laju pertumbuhan ekonomi suatu 
bangsa dapat diukur dengan menggunakan laju pertumbuhan PDRB Atas Dasar Harga Konstan (ADHK) (Sukirno, 2010). Tingginya tingkat persaingan antarnegara tidak hanya berdampak pada perekonomian Indonesia secara keseluruhan, tetapi berdampak langsung pada perekonomian daerah pada khususnya setelah pemberlakuan otonomi daerah dan desentralisai fiskal. Persaingan semakin tajam dalam meningkatkan daya saing daerah menuntut pemerintah daerah untuk menyiapkan daerahnya agar mampu meningkatkan daya saing daerah. Keberhasilan daerah untuk meningkatkan daya saing tergantung dari kemampuan daerah dalam merumuskan kebijakan yang berkaitan dengan faktor penentu daya saing ekonomi (Sukanto, 2009). Daya saing daerah mempunyai arti yang sama dengan daya saing nasional. Pengertian mencakup wilayah yang lebih luas seperti pulau atau propinsi, atau wilayah yang lebih kecil seperti kabupaten/kota. Perkembangan tersebut dapat dilihat dari pengukuran kinerja yang dilakukan.

Pengukuran kinerja merupakan upaya membandingkan tujuan yang ingin dicapai pada waktu yang telah ditentukan dengan perkembangan pencapaian yang sedang diamati pada suatu waktu atas suatu materi perencanaan yang ditunjukkan oleh indikator (Bappenas, 2009). Indikator adalah suatu alat ukur untuk menggambarkan tingkatan capaian suatu sasaran atau target yang telah ditetapkan ketika melakukan perencanaan awal, dan dapat merupakan variabel kuantitatif atau kualitatif dengan tujuan untuk memperbandingkan tingkat kemajuan pembangunan atau tingkat kesejahteraan masyarakat antar wilayah atau negara dan mengetahui corak pembangunan setiap negara atau suatu wilayah (Arsyad, 2010). Indikator tersebut dapat bersifat fisikal, ekonomi, sosial, dan politik.

Indikator pada penelitian ini mengacu pada indikator berdasarkan PP No. 129 Tahun 2000 tentang Persyaratan Pembentukan dan Kriteria Pemekaran, Penghapusan dan Penggabungan Daerah dan Usulan Indikator Kinerja Pembangunan Daerah hasil penelitian Bappenas yang bekerja sama dengan UNDP dalam Laporan Studi Pengembangan Indikator Pembangunan Daerah dan berdasarkan pada penelitian sebelumnya terkait dengan kinerja pembangunan ekonomi daerah (Putri, 2017).

\section{Metode Penelitian}

Data yang digunakan pada penelitian ini adalah data sekunder yakni data yang diperoleh secara tidak langsung atau diperoleh dari sumber yang sudah ada. Data tersebut bersumber dari Badan Pusat Statistik Provinsi Sulawesi Selatan.

Deskripsi variabel yang akan digunakan dalam penelitian ini adalah sebagai berikut .

Tabel 2 Variabel Penelitian

\begin{tabular}{cl}
\hline Variabel & \multicolumn{1}{c}{ Keterangan } \\
\hline$X_{1}$ & Laju pertumbuhan ekonomi \\
$X_{2}$ & Pendapatan asli daerah \\
$X_{3}$ & Persentase PAD terhadap pendapatan daerah \\
$X_{4}$ & Kontribusi sektor primer terhadap PDRB kabupaten/kota \\
$X_{5}$ & Kontribusi sektor sekunder terhadap PDRB kabupaten/kota \\
$X_{6}$ & Kontribusi sektor tersier terhadap PDRB kabupaten/kota \\
$X_{7}$ & Persentase PDRB kabupaten/kota terhadap PDRB provinsi \\
$X_{8}$ & Tingkat partisipasi angkatan kerja \\
$X_{9}$ & Persentase penduduk miskin \\
$X_{10}$ & PDRB per kapita \\
$X_{11}$ & Jumlah penduduk \\
$X_{12}$ & Angka melek huruf \\
$X_{13}$ & Angka harapan hidup \\
$X_{14}$ & Rata rata lama sekolah \\
$X_{15}$ & Pengeluaran perkapita \\
\hline
\end{tabular}

Adapun tahapan teknik analisis yang akan dilakukan yaitu:

1) Melakukan analisis deskriptif untuk melihat karakteristik variabel-variabel indikator kinerja pembangunan ekonomi daerah setiap kabupaten/kota di provinsi Sulawesi Selatan

2) Melakukan transformasi kedalam bentuk baku karena variabel yang digunakan memiliki satuan berbeda

3) Melakukan standarisasi data. 
4) Membuat matriks jarak berdasarkan ukuran kemiripan antar objek

5) Membentuk anggota ensemble dengan melakukan pengelompokan menggunakan metode hierarki dan non hierarki. Penentuan kelompok berdasarkan subjektif oleh peneliti.

6) Membuat tabulasi anggota ensemble. Tabulasi ini merupakan solusi kelompok yang dihasilkan dari setiap metode.

7) Membentuk matriks kesamaan dengan algoritma Link-Based Cluster Ensemble.

8) Mentransfornasi matriks kesamaan yang terbentuk menjadi matriks jarak.

$$
d_{i j}=1-\operatorname{CTS}\left(x_{i}, x_{j}\right)
$$

9) Melakukan pengelompokan berdasarkan matriks jarak menggunakan metode keterhubungan tunggal (single linkagelnearst neighbour), keterhubungan menyeluruh (complete linkagelfurthest neighbour), dan keterhubungan rataan (average linkage) untuk mendapatkan solusi kelompok akhir.

10) Melakukan evaluasi kualitas pengelompokan Cluster Ensemble.

11) Mendeskripsikan masing-masing kelompok berdasarkan karakteristik variabelnya.

\section{Hasil dan Pembahasan}

\subsection{Karakteristik Data}

Berdasarkan variabel penelitian yang digunakan dari indikator kinerja pembangunan ekonomi daerah Provinsi Sulawesi Selatan tahun 2018 diketahui sampel penelitian sebanyak 24 yakni kabupaten/kota di Provinsi Sulawesi Selatan. Karakteristik data dijelaskan dalam bentuk deskriptif untuk menggambarkan setiap variabel.

Tabel 3 Karakteristik Data

\begin{tabular}{llllll}
\hline Variabel & N & Minimum & Maksimum & Rata-Rata & Stddev \\
\hline Laju Pertumbuhan Ekonomi (\%) & 24 & 1.07 & 8,90 & 6,53 & 1,97 \\
Pendapatan Asli Daerah (Juta Rupiah) & 24 & 58562 & 1483713 & 195748 & 278726,72 \\
Persentase PAD Terhadap Pendapatan & 24 & 5,24 & 36,03 & 11,68 & 6,12 \\
Daerah (\%) & 24 & 0,50 & 53,83 & 32,49 & 14,78 \\
Kontribusi Primer PDRB Kab/Kota (\%) & 24 & 24 & 8,57 & 9,79 \\
Kontribusi Sekunder PDRB Kab/Kota (\%) & 24 & 2,04 & 49,40 & 12,60 & 5,38 \\
Kontribusi Tersier PDRB Kab/Kota (\%) & 24 & 2,69 & 23,66 & 4,20 & 6,75 \\
Persentase PDRB Kab/Kota Terhadap & 24 & 1,26 & 35,14 & 4,20 & 2,71 \\
Provinsi (\%) & 24 & 87,81 & 98,34 & 95,56 & 3,26 \\
Tingkat Partisipasi Angkatan Kerja (\%) & 24 & 4,60 & 16,20 & 10,22 & 17,65 \\
Persentase Penduduk Miskin (\%) & 24 & 25,06 & 106,23 & 45,05 & 290334,81 \\
PDRB Perkapita (Juta Rupiah) & 24 & 132280 & 1508154 & 365415 & 3,33 \\
Jumlah Penduduk (Jiwa) & 24 & 85,82 & 97,71 & 91,39 & 2,03896 \\
Angka Melek Huruf (\%) & 24 & 65,89 & 73,09 & 69,0025 & 1,20 \\
Angka Harapan Hidup (\%) & 24 & 6,21 & 11,09 & 7,89 & 2962,67 \\
Rata2 Lama Sekolah (Tahun) & 24 & 7087 & 16597 & 10189 & \\
Pengeluaran Perkapita (Ribu Rupiah) & & & & &
\end{tabular}

\subsection{Transformasi Data}

Berdasarkan 24 sampel dari 15 variabel penelitian yang berupa data numerik dan memiliki rentang nilai yang beragam dengan satuan atribut yang beragam pula maka perlu dilakukan standarisasi data sehingga setiap atribut dapat secara proporsioal memiliki kontribusi terhadap hasil akhir penelitian. 


\subsection{Membentuk Matriks Jarak}

Tahap pembentukan matriks jarak antar objek pengamatan menggunakan jarak Euclidien. Jarak yang diperoleh dari 24 sampel pengamatan dinyatakan dalam matriks yang berukuran $24 \times 24$ pada Tabel 4 dengan baris sebagai sampel dan kolom sebagai jarak antar pengamatan.

Tabel 4 Hasil Matriks Jarak

\begin{tabular}{ccccccc}
\hline & 1 & 2 & 3 & 4 & $\cdots$ & 24 \\
\hline 1 & 0 & & & & & \\
2 & 4,59 & 0 & & & & \\
3 & 3,50 & 4,97 & 0 & & & \\
4 & 3,19 & 4,62 & 3,50 & 0 & & \\
$\vdots$ & $\vdots$ & $\vdots$ & $\vdots$ & $\vdots$ & $\ddots$ & \\
24 & 6,56 & 6,76 & 6,02 & 7,54 & $\cdots$ & 0 \\
\hline
\end{tabular}

Jarak euclidien berisikan kemiripan antar jarak pengamatan atau pasangan objek. Sebagai contoh, untuk nilai pada baris kedua kolom pertama tersebut menunjukkan bahwa kedekatan antara setiap pasangan objek bernilai 4,59.

\subsection{Pengelompokan (Clustering)}

Tahap pengelompokan dilakukan dengan menggunakan metode hierarki dan non hierarki, pada penelitian ini metode hierarki menggunakan jarak euclidien sebagai penentuan jarak antar pasangan objek. Meotde hierarki yang digunakan yakni keterhubungan tunggal (single linkagelnearst neighbour), keterhubungan menyeluruh (complete linkagelfurthest neighbour), pautan median, keterhubungan rataan (average linkage), dan ward. Sedangkan metode non hierarki menggunakan data standarisasi yakni k-means. Selanjutnya dalam pengelompokan dilakukan masing masing pembentukan inisiasi awal dengan membentuk 2, 3 dan 4 kelompok disetiap metode yang akan digunakan.

\subsection{Cluster Ensemble}

Penelitian ini akan mengelompokkan kabupaten/kota di Provinsi Sulawesi Selatan berdasarkan indikator kinerja pembangunan ekonomi daerah. Tahap pengelompokan awal akan membentuk kelompok sesuai dengan metode konvensional (hierarki dan non hierarki) yang digunakan dan hasilnya membentuk solusi yang beragam berdasarkan inisiasi penentuan kelompok awal. Selanjutnya hasil disetiap metode disebut sebagai anggota ensemble yakni sebanyak 6 metode, diantaranya keterhubungan tunggal (single linkage/nearst neighbour), keterhubungan menyeluruh (complete linkagelfurthest neighbour), pautan median (centroid), keterhubungan rataan (average linkage), ward, dan k-means.

Kesamaan hasil solusi pengelompokan dari metode yang digunakan diperlihatkan dalam Tabel 5 yang selanjutnya disebut (anggota Ensemble).

Tabel 5 Pembagian kelompok yang sama

\begin{tabular}{|c|c|}
\hline $\begin{array}{l}\text { Kesamaan } \\
\text { Kelompok }\end{array}$ & Metode \\
\hline 2 & $\begin{array}{l}\text { keterhubungan tunggal (single linkagelnearst neighbour), keterhubungan } \\
\text { menyeluruh (complete linkagelfurthest neighbour), pautan median (centroid), } \\
\text { keterhubungan rataan (average linkage), dan ward }\end{array}$ \\
\hline 3 & $\begin{array}{l}\text { - hierarki keterhubungan tunggal (single linkagelnearst neighbour), } \\
\text { keterhubungan rataan (average linkage) dan pautan median (centroid) } \\
\text { - } \quad \text { keterhubungan menyeluruh (complete linkagelfurthest neighbour), dan ward }\end{array}$ \\
\hline 4 & $\begin{array}{l}\text { keterhubungan tunggal (single linkage/nearst neighbour), keterhubungan rataan } \\
\text { (average linkage), dan pautan median (centroid) }\end{array}$ \\
\hline
\end{tabular}


Dari hasil tersebut menyatakan pembentukan kelompok dengan solusi 2 kelompok menghasilkan pembagian kelompok yang sama terhadap setiap metode yang digunakan kecuai metode non hierarki (k-means), namun berbeda dengan pembagian kelompok berdasarkan pembentukan solusi 3 dan 4 kelompok yang beberapa memiliki hasil yang sama dan berbeda. Dari setiap solusi yang dihasilkan akan dibentuk anggota ensemble baru dengan menggunakan solusi yang sama sebagai satu solusi saja. Oleh karena itu, solusi pengelompokan yang digunakan sebagai anggota ensemble yang terbentuk berjumlah 9 solusi.

Selanjutnya dari anggota ensemble yang terbentuk ditransformasikan menjadi Binary Association Matrix (BM). Dinyatakan membentuk matriks berukuran $24 \times 29$ dengan 24 merupakan baris jumlah pengamatan atau jumlah sampel dan 29 sebagai kolom label atau fungsi pembentukan Binary Association Matrix (BM) untuk setiap anggota ensemble.

Dari pembentukan tersebut selanjutnya menghasilkan matriks kesamaan Connected Triple Based Similarity (CTS) dengan matriks $S$ ukuran $24 \times 24$.

$$
S=\left[\begin{array}{cccccc}
1 & & & & & \\
1,21 & 1 & & & & \\
1,21 & 1,21 & 1 & & \\
1,21 & 1,21 & 1,21 & 1 & & \\
\vdots & \vdots & \vdots & \vdots & \ddots & \\
0,61 & 0,61 & 0,61 & 0,61 & \ldots & 1
\end{array}\right]
$$

Dari matriks tersebut dengan diagonal matriks bernilai 1 apabila label objek ke-i dan ke-j pada matriks BM bernilai sama. Pada pembentukan nilai kesamaan lainnya merupakan nilai kesamaan antara solusi kelompok objek ke-i dengan label objek ke-j pada tingkat kepercayaan $(\mathrm{DC})=0,9$ yakni tingkat kepercayaan antara dua objek non-identik yang digunakan.

Solusi pengelompokan akhir didapatkan dari matriks jarak yang telah terbentuk lalu kemudian divisualisasikan kedalam bentuk dendogram yakni menggunakan metode keterhubungan tunggal (single linkagelnearst neighbour), keterhubungan menyeluruh (complete linkagelfurthest neighbour), dan keterhubungan rataan (average linkage) sebagai pembanding akhir dari beberapa metode yang digunakan. Pemotongan kelompok dilakukan secara subjektifitas dari peneliti.

Sesuai dengan hal tersebut pemotongan yang terbentuk secara umum membentuk 3 kelompok yang dapat dilihat dari persamaan karakteristik setiap kelompok. Hasil pengelompokan akhir yang terbentuk menggunakan cluster ensemble yang terdiri dari 3 kelompok. Kelompok tersebut berdasarkan 24 sampel penelitian yakni Kabupaten/Kota di Provinsi Sulawesi Selatan.

Tabel 6 Kelompok Akhir

\begin{tabular}{ll}
\hline Kelompok 1 & Makassar \\
\hline Kelompok 2 & Pangkep, Pare-Pare, Palopo \\
\hline Kelompok 3 & Maros, Luwu Timur, Sinjai, Bulukumba, Gowa, Takalar, Jeneponto, Bantaeng, \\
& Sidrap, Bone, Enrekang, Luwu, Kep. Selayar, Toraja Utara, Pinrang, Wajo, \\
& Soppeng, Barru, Tana Toraja, Luwu Utara \\
\hline
\end{tabular}

\subsection{Evaluasi Kualitas Kelompok}

Pengelompokan dilakukan dengan menggunakan cluster ensemble sesuai dengan 24 sampel penelitian yakni kabupaten/kota di Provinsi Sulawesi Selatan berdasarkan indikator kinerja pembangunan ekonomi daerah. Evaluasi kualitas kelompok dilakukan untuk melihat hasil yang terbaik dari setiap metode pengelompokan yang digunakan. keterhubungan tunggal (single linkage/nearst neighbour), keterhubungan menyeluruh (complete linkagelfurthest neighbour), pautan median, keterhubungan rataan (average linkage), ward dan k-means akan dibandingkan dengan cluster ensemble yang selanjutnya akan terbagi menjadi 3 evaluasi pengelompokan yakni hierarki, non hierarki, dan cluster ensemble. Evaluasi kualitas kelompok yang digunakan ialah compactness (CP) dan Davies-Bouldin (DB). 
Tabel 7 Hasil Evaluasi Kualitas Kelompok

\begin{tabular}{lll}
\hline Metode & CP & DB \\
\hline Hierarki & 0,31 & 0,62 \\
Non Hierarki & 0,84 & 1,35 \\
Cluster Ensemble & 0,22 & 0,54 \\
\hline
\end{tabular}

Nilai indeks masing masing evaluasi kualitas kelompok untuk setiap metode memperlihatkan hasil yang berbeda. Compactness (CP) dan Davies Bouldin (DB) menunjukkan bahwa diantara metode yang ada hasil dari cluster ensemble memiliki nilai terendah masing masing 0,22 dan 0,54. Berdasarkan dari itu dapat dinyatakan bahwa hasil pengelompokan yang lebih tepat digunakan yakni cluster ensemble pada indikator kinerja pembangunan ekonomi daerah dibanding dengan metode hierarki dan non hierarki.

\subsection{Pembahasan}

Kelompok akhir yang terbentuk kemudian dideskripsikan sesuai dengan karakteristik setiap kelompok dalam bentuk plot profil dan nilai rataan setiap kelompok. Kemiripan profil antar kelompok dapat dilihat berdasarkan kesejajaran plot profil setiap variabel untuk setiap kelompok. Untuk mendeskripiskan hal tersebut maka digunakan nilai rataan dari setiap variabel penelitian sesuai dengan kelompok akhir.

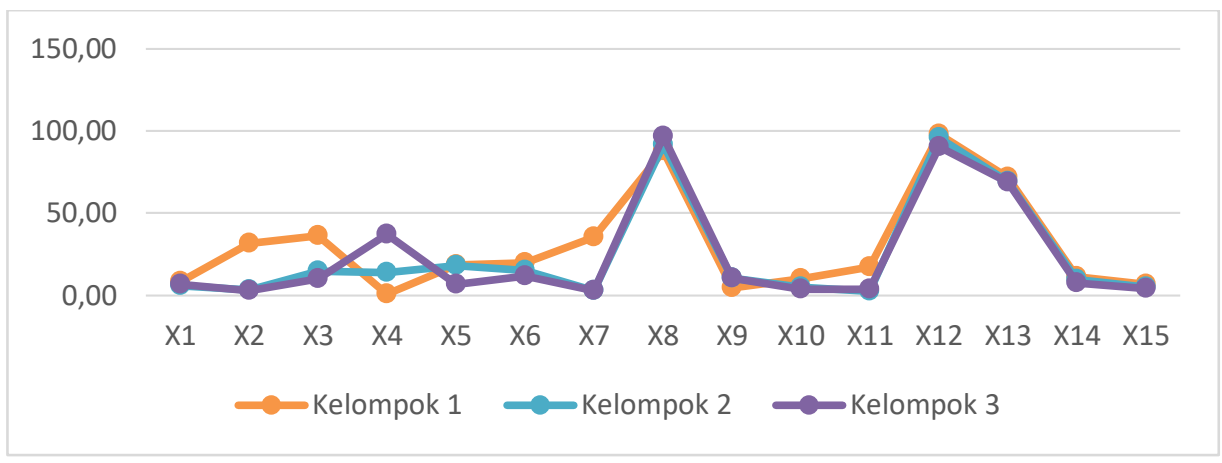

Gambar 2 Plot Profil Variabel

Berdasarkan gambar tersebut yang dihasilkan memiliki pola profil yang berbeda beda. Variabel indikator kinerja pembangunan ekonomi daerah tidak semuanya mengindikasikan bahwa titik knot tertinggi merupakan variabel dengan kelompok yang lebih baik dibandingkan kelompok lainnya. Misalkan pada variabel persentase penduduk miskin $\left(\mathrm{X}_{9}\right)$ yang dapat dikatakan baik apabila kabupaten/kota tersebut memiliki knot yang rendah dan untuk variabel lainnya memiliki knot tertinggi yang merupakan kelompok dengan kinerja pembangunan ekonomi daerah yang baik dibandingkan dengan kelompok dari pembentukan knot lainnya pada setiap variabel.

Nilai rata rata untuk semua indikator kinerja pembangunan ekonomi daerah pada kelompok pertama yang hanya terdiri dari satu kabupaten/kota yakni kota Makassar lebih tinggi dibandingkan dengan kelompok lainnya kecuali pada variabel kontribusi sektor primer terhadap PDRB kabupaten/kota dan tingkat partisipasi angkatan kerja. Oleh karena itu, kelompok pertama dapat dikatakan sebagai kelompok yang memiliki karakteristik kinerja pembangunan ekonomi daerah yang paling baik dibandingkan kelompok kedua dan ketiga dari nilai rata rata yang dominan dari pembentukan kelompok akhir tiap variabel penelitian yang digunakan.

Kelompok kedua yang terdiri dari kabupaten Pangkep, kota Pare-Pare, dan Kota Palopo. Hasil dari nilai rataan menyatakan bahwa kelompok kedua memiliki karakteristik kinerja pembangunan ekonomi daerah yang tidak lebih baik dari kelompok yang pertama bila dibandingkan dengan nilai rata rata kelompok pertama. Namun kelompok kedua memiliki beberapa nilai rata rata variabel yang rendah dari kelompok ketiga yakni pada variabel laju pertumbuhan ekonomi, persentase PDRB kabupaten/kota terhadap PDRB provinsi, dan jumlah penduduk tetapi secara dominan nilai rata rata kelompok kedua tidak lebih rendah dari kelompok ketiga. 
Kelompok ketiga terdiri dari Maros, Luwu Timur, Sinjai, Bulukumba, Gowa, Takalar, Jeneponto, Bantaeng, Sidrap, Bone, Enrekang, Luwu, Kep. Selayar, Toraja Utara, Pinrang, Wajo, Soppeng, Barru, Tana Toraja, dan Luwu Utara yang semuanya meliputi kabupaten di Provinsi Sulawesi Selatan kecuali kabupaten Pangkep. Pada kelompok ketiga terdapat variabel dengan nilai rata rata yang tinggi yakni variabel kontribusi sektor primer terhadap PDRB kabupaten/kota dan tingkat partisipasi angkatan kerja pada kelompok pertama dan pada variabel variabel laju pertumbuhan ekonomi, persentase PDRB kabupaten/kota terhadap PDRB provinsi, dan jumlah penduduk pada kelompok kedua namun tidak untuk variabel lainnya yang dominan lebih rendah dibandingkan kelompok pertama dan kedua.

Jika diurutkan berdasarkan besar kecilnya nilai rata-rata indikator kinerja pembangunan ekonomi daerah untuk masing masing kelompok, kelompok pertama merupakan kelompok yang memiliki karakteristik kinerja pembangunan ekonomi daerah yang terbaik. Dibandingkan dengan kelompok lainnya yakni kelompok kedua yang nilai rata-ratanya tidak lebih besar dari kelompok pertama dan tidak lebih kecil dibandingkan kelompok yang ketiga. Sehingga kelompok ketiga merupakan kelompok yang memiliki kinerja pembangunan ekonomi daerah yang kurang dibandingkan kelompok lainnya.

\section{Kesimpulan}

Tujuan dari penelitian ini adalah untuk mengelompokkan kabupaten/kota di Provinsi Sulawesi Selatan berdasarkan indikator kinerja pembangunan ekonomi daerah dengan menggunakan metode Cluster Ensemble. Dari hasil penelitian ini dapat disimpulkan bahwa Cluster Ensemble lebih baik dibandingkan dengan metode pengelompokan hierarki dan non hierarki yang menghasilkan solusi yang beragam dengan membandingkan hasil dendogram dan evaluasi kualitas kelompok yang menyatakan Cluster Ensemble memiliki pembentukan kelompok yang lebih baik dibandingkan metode hierarki dan non hierarki. Solusi akhir hasil Cluster Ensemble menghasilkan 3 kelompok yang memuat 24 sampel kabupaten/kota di Provinsi Sulawesi Selatan.

Hasil pengelompokan menunjukkan bahwa kelompok pertama yakni kota Makassar lebih baik dalam kinerja pembangunan ekonomi daerah dibandingkan kelompok kedua yang terdiri dari kabupaten Pangkep, kota Pare-Pare dan kota Palopo yang rendah. Namun pada kelompok ketiga yang terdiri dari kabupaten Maros, Luwu Timur, Sinjai, Bulukumba, Gowa, Takalar, Jeneponto, Bantaeng, Sidrap, Bone, Enrekang, Luwu, Kep. Selayar, Toraja Utara, Pinrang, Wajo, Soppeng, Barru, Tana Toraja, dan Luwu Utara merupakan kelompok yang terendah dibandingkan dengan kelompok pertama dan kedua dalam kinerja pembangunan ekonomi daerah tetapi kontribusi sektor primer terhadap PDRB kabupaten/kota dan tingkat partisipasi angkatan kerja dikelompok ketiga ini lebih baik dibandingkan kelompok pertama dan laju pertumbuhan ekonomi, persentase PDRB kabupaten/kota terhadap PDRB provinsi, dan jumlah penduduk pada kelompok kedua.

\section{References}

Arsyad, L. (2010). Ekonomi Pembangunan dan Pembangunan Ekonomi. Yogyakarta: UPP STIM YKPN.

Babin, B. J., \& Anderson, R. E. (2014). Multivariate Data Analysis Joseph F. Hair Jr. William C. Black Seventh Edition (7th ed.). British Library Cataloguing-in-Publication Data.

Badan Pusat Statistik. (2019). Laporan Perekonomian Indonesia. Jakarta: Badan Pusat Statistik. www.bps.go.id/publication/2019//09/16/laporan-perekonomian-indonesia-2019

Badan Pusat Statistik. (2019). Produk Domestik Regional Bruto Kabupaten/Kota Se Provinsi Sulawesi Selatan Menu. Makassar: Badan Pusat Statistik Provinsi Sulawesi Selatan. www.sulsel.bps.go.id/publication/ 2019/08/12/produk-domestik-regional-bruto-kabupaten-kota-se-sulawesi-selatan-2014-2018

Badan Pusat Statistik. (2018). Statistik Daerah Provinsi Sulawesi Selatan 2018. Makassar: Badan Pusat Statistik Provinsi Sulawesi Selatan. www.sulsel.bps.go.id/publication/2018/09/26/statistik-daerah-provinsi- sulawesiselatan-2018

Badan Pusat Statistik. (2019). Statistik Keuangan Pemerintah Daerah Kabupaten/Kota Di Provinsi Sulawesi Selatan 2017/2018. Makassar: Badan Pusat Statistik Provinsi Sulawesi Selatan. www.sulsel.bps.go.id/publication/2019/08/20/statistik-keuangan-pemerintah-daerah-kabupaten-kota-diprovinsi-sulawesi-selatan-2017-2018

Badan Pusat Statistik. (2019). Sulawesi Selatan dalam Angka. Makassar: Badan Pusat Statistik Provinsi Sulawesi Selatan. www.sulsel.bps.go.id/publication/2019/08/16/sulawesi-selatan-dalam-angka-2019 
Badan Perencanaan Pembangunan Nasional (BAPPENAS) (2009). Pedoman Evaluasi dan Indikator Kinerja Pembangunan. Jakarta. www.bappenas.go.id

Bejar, J. Unsupervised learning aims the same goal: Consensus clustering or Clustering Ensembel. Consensus Clustering. Diakses pada tanggal 11 Februari 2020. www.cs.upc.edu

Everitt, B. S., Landau, S., Leese, M., \& Stahl, D. (2011). Cluster Analysis. UK: Wiley.

Hu, X., \& Yoo, I. (2004). Cluster Ensemble and Its Apllications in Gene Expression Analysis. 2nd Asia-Pacific Bioninformatics Conference.

Iam-on, N., \& Garrett, S. (2010). LinkClue: A MATLAB Package for Link-Based Cluster Ensembles. Journal of Statistical Software

Johnson, R. A., \& Winchern, D. W. (2007). Applied Multivariate Statistical Analysis.

Mattjik, A. A., \& Sumertajaya, I. M. (2011). Sidik Peubah Ganda (G. N. A. Wibawa \& A. F. Hadi, Eds.). Bandung: IPB Press.

Nuraidah, S. (2014). Cluster Ensemble Dalam Penggerombolan Kabupaten/Kota Provinsi Jawa Barat Berdasarkan Indikator Penddikan SMA/SMK/MA. Skripsi: Institut Pertanian Bogor.

Putri, K. R. (2017). Klasifikasi Kabupaten/kota Di Provinsi Jawa Timur Berdasarkan Indikator Kinerja Pembangunan Ekonomi Daerah Dengan Metode Analisis Cluster. Skripsi: Institut Teknologi Sepuluh Nopember

Ristiyanti. (2017). Cluster Ensemble Dalam Pengelompokan Provinsi Di Indonesia Berdasarkan Indikator Pelayanan Kesehatan Ibu Hamil. Skripsi: Institut Pertanian Bogor

Strehl, A., \& Ghosh, J. (2002). Cluster Ensembles - A Knowledge Reuse Framework for Combining Partitionings.

Sukanto. (2009). Analisis Daya Saing Ekonomi Antar Daerah di Provinsi Sumatera Selatan. Jurnal Ekonomi Pembangunan, 86-102.

Sukirno, S. (2010). Teori Pengantar Makroekonomi Edisi Ketiga. Jakarta: PT. Raja Grasindo Persada.

Supranto. (2004). Analisis Multivariat Arti dan Interpretasi. Jakarta: Rineka Cipta.

Susanto, H. T. (2009). Cluster Analysis. In H. T. Sutanto (Ed.), Cluster Analysis (pp. 978-979). Yogyakarta: Seminar Nasional Matematika dan Pendidikan Matematika.

Tiro, M. A., Sukarna, \& Aswi. (2010). Statistika Deskriptif Peubah Banyak. Makassar: Andira Publisher.

Todaro, M. P. (2003). Pembangunan Ekonomi Di Dunia Ketiga. Alih Bahasa: Aminuddin dan Drs. Mursid. Jakarta: Ghalia Indonesia 